\title{
The Association of Hematological Inflammatory Markers and Psychological Function Among in COVID-19 Patients: a Cross Sectional Study
}

\section{Zahra Khorasanchi}

Mashhad University of Medical Sciences

Mohammad Rashid Mayvan

Mashhad University of Medical Sciences

Elahe Hasanzadeh

Mashhad University of Medical Sciences

Maryam Allahyari

Mashhad University of Medical Sciences

\section{Reza Rezvani Moghadam}

Mashhad University of Medical Sciences

Parisa Asadiyan-Sobhan

Islamic Azad University

Payam Sharifan

Mashhad University of Medical Sciences

Nafiseh Afkhami

Islamic Azad University

Naiemeh Varaste

Mashhad University of Medical Sciences

Gordon Ferns

Brighton and Sussex Medical School

Majid Ghayour Mobarhan ( $\square$ ghayourm@mums.ac.ir )

Mashhad University of Medical Sciences

\section{Research Article}

Keywords: Anxiety, COVID-19, Depression, Haematological biomarker, Stress

Posted Date: January 31st, 2022

DOI: https://doi.org/10.21203/rs.3.rs-1174423/v1

License: () (i) This work is licensed under a Creative Commons Attribution 4.0 International License. Read Full License 


\section{Abstract}

Background: Due to high inflammation and mental health disorders in Covid-19 patients, we aimed to investigate the relationship between blood inflammatory markers such as WBC, RDW, NLR and PLR and psychological function in COVID-19 patients.

Method: The current cross-sectional study and psychological function and a complete blood count (CBC) were measured on 120 COVID-19 patients aged $>30$ years from the Imam Reza hospital in Mashhad, Iran. Depression, anxiety and stress of participants were evaluated using DASS questionnaire. Also Quality of life, insomnia and sleep quality were measured via SF-36, Insomnia Severity Index and Pittsburgh Sleep Quality Index questionnaire, respectively.

Result: No blood parameters were significantly associated with depression, sleep disorders and quality of life $(\mathrm{P}>0.05)$, but in $\mathrm{MCHC}$, WBC and PLR anxiety showed a significant relationship $(p<0.05)$. In the stress subgroup, only RPR was associated with stress $(p<0.05)$. In linear regression between hematological parameters and psychological score indicated that RDW and PLR were significantly associated with depression ( $p=0.045$ and 0.016 respectively) and anxiety scores $(p=0.038$ and 0.010 respectively). PLR was also associated with stress $(p=0.012)$.

Conclusion: This study showed a positive association between depression/anxiety/stress symptoms and levels of hematological inflammatory markers including PLR and RDW.

\section{Background}

The 2019 coronavirus COVID-19 pandemic, has affected more than 170 million individuals resulting in 3.5 million deaths globally by May 2021[1, 2]. In addition to the impact on physical health, has had taken a toll on mental health as a result of fear of illness and hospitalization and social distancing efforts may have a unique and significant influence on mental health. Given the significance of stress in the etiology of anxiety and depressive disorders, the prevalence of these diseases may rise due to intensified stress related to COVID-19. Preliminary research also suggests that these symptoms and disorders may be linked to more severe COVID-19 progression [3]. Mental health of COVID-19 hospitalized patients during the epidemic has been reported in previous studies. In this context, patients who were diagnosed with COVID-19 were more likely to have psychological concerns such as fear of disease progression, disability, or higher mortality. It is essential to investigate the prevalence and severity of anxiety and depression in COVID-19 infected patients [4]. In addition to COVID-19 situations, perceived stress related to COVID-19- expected to have a significant increasing prevalence in poorer mental health outcomes.

When early response pro-inflammatory cytokines are overproduced, it may result in a cytokines storm, which increases the risk of vascular hyper permeability, multi organ failure and mortality if the cytokine concentration are not decreased [5]. The inflammatory response is mediated by phagocytic cells such as monocytes (MON) and neutrophils (NEU), as well as cytokines, which are important components of the immune system. In anxiety and related disorders, central and peripheral immune system cells release cytokines and cause inflammation in response to increased stress [6]. Inflammation and anxiety disorders are linked, which hematological parameters are also thought to be a useful marker in the follow-up of patients with anxiety disorders [7]. Systemic inflammation has been linked to depression and anxiety, two common mood disorders [8]Several studies have found a link between depression and higher levels of pro-inflammatory cytokines, and there is some correlation between anxiety and inflammation $[9,10]$.

The white blood cell count (WBC) is a non-specific inflammatory marker that is usually measured as part of a complete blood count (CBC) panel. A high WBC count has been linked to a variety of diseases, including hypertension, diabetes, and atherosclerotic cardiovascular disease [11]Moreover, numerous studies reported that having a higher WBC count is associated with an increased risk of all-cause cardiac disease and cancer mortality [12]. The quantitative measure of anisocytosis, red cell distribution width (RDW), is a simple, low-cost parameter that is routinely reported as part of the CBC test [13]. Previous research has found a significant association between RDW and inflammatory markers such as hs-CRP and erythrocyte sedimentation rate, indicating that increased RDW may be the result of an underlying inflammatory state that is associated with negative outcomes [14]. The findings of one study suggested that RDW should be included in routine laboratory monitoring and assessment of COVID-19 [15].

In COVID-19 confirmed cases, reported that lymphopenia, eosinopenia, neutrophilia, leucocytosis and decline of hemoglobin. When compared to the control group, these parameters demonstrated a significant deterioration in critically acute ICU patients [16]. Increased NLR has been reported as a significant risk factor for clinical complications. Despite the fact PLR did not show a 
significant difference [16]. Previous research has found that personal experiences with COVID-19 diagnosis, mortality in acquaintances, and COVID-19-related stress are related to a significantly increased risk of emotional disorder symptomatology, and that the COVID-19 pandemic may result in an increase in demand for mental health services [17].

In contrast to measuring peripheral cytokine levels, studies on this topic have found that measuring peripheral blood cells, which are the source of some of these cytokines, by complete blood count is a cheap, easy, and rapid procedure. Leukocytes, which are counted as part of a complete blood count, play an important role in inflammation. By secreting cytokines, NEU and MON play an important role in the inflammatory response [18]. The neutrophil/lymphocyte ratio (NLR), which is determined by the ratio of these two key cells participating in the inflammatory response, has been accepted as a measure of systemic inflammatory response [18]. NLR is recognized as an inflammatory response and prognostic factor in a variety of chronic diseases, including autoimmune, cardiovascular, and respiratory diseases $[19,20]$. NLR has been reported to be higher in several psychiatric diseases, such as mood disorders, anxiety disorders, and schizophrenia, than in healthy adults, and has already been considered as a biomarker of increased inflammatory response [21, 22]. Platelets are another essential cell type that is counted in a complete blood count (PLT). Active PLT, in collaboration with MON and leukocytes, play a key role in implementing and sustaining inflammation by facilitating the release of inflammatory cytokines [23]. Platelet/lymphocyte ratio (PLR) is a biomarker used as a diagnostic of chronic inflammation, similar to NLR, and is useful in a number of disease groups, especially autoimmune illnesses and cancer [19, 24]. And is often used to diagnose psychiatric diseases [25].

In the present study, due to high inflammation and mental health disorders in Covid-19 patients, we aimed to investigate the relationship between blood inflammatory markers such as WBC, RDW, NLR and PLR and depression, anxiety, stress, and quality of life in COVID-19 patients. Our study hypothesized that there was a relationship between psychiatric disorders in Covid-19 patients and inflammation using blood parameters, which is a cheap, fast, and easy method.

\section{Methods And Materials Study design}

The current cross-sectional study was carried out during 2021 within a sample of COVID-19 patients from the Imam Reza hospital in Mashhad, Iran. The total subjects included 120 covid-19 patients aged $>30$ years. The exclusion criteria were: cancer, autoimmune diseases, hepatic or renal failure, metabolic bone disease and without anti-depressant drug treatment during the previous 6 months.

\section{General and clinical characteristics}

Demographics and clinical characteristic including age, smoking status, comorbidity data were collected from each participant at the baseline by trained interviewers.

\section{Blood Collection and Biochemical Measurements}

A CBC including red blood cell (RBC), hemoglobin (HGB), hematocrit (HCT), mean corpuscular volume (MCV), mean corpuscular hemoglobin $(\mathrm{MCH})$ and mean corpuscular hemoglobin concentration $(\mathrm{MCHC})$, platelet (PLT), platelet distribution width (PDW), mean platelet volume (MPV), RDW, and WBC was measured by using an auto hematology analyzer (Sysmex K-800) for each individual.

\section{Depression anxiety stress scales (DASS)}

Depression anxiety stress scales (DASS) is an accurate and valid tool to evaluate mood status [26]. This tool is a questionnaire that consists of three subscales includes 7 questions, generally consists 21 items. Each question is ranged on a four point (0-3) Likert scale to identify the severity of mood disorder including depression, anxiety and stress. Score of each item must be doubled because of DASS 21 is a brief version of DASS 42. In this tool a higher score shows higher degree of negative mood status and lower score indicates lower degree of negative emotion. The reliability and validity of DASS has been previously reported in Iranian population [27]. The scores for depression, anxiety and stress were divided into 2 classifications: No or minimal scores, some degree of mood disorder. Based on the scores obtain from each item determined as follows: $(\leq 9$, No), (>9, some degree of depression), ( $\leq$ 7$, No), (> 7, some degree of anxiety), ( $\leq 14, \mathrm{No})$, ( $>14$ some degree of stress).

\section{Insomnia Severity Index (ISI)}


The ISI is a seven-item self-report tool for determine of the insomnia symptom and its consequences. The dimensions measured are: severity of sleep onset, sleep preservation, early morning awakening problems, sleep dissatisfaction, interference of sleep difficulties with daytime functioning, noticeability of sleep problems by others and distress caused by the sleep difficulties [28]. Each item according to severity scored on $0-4$ scale. The total scale ranging from 0 to 28 and explained as follows: no insomnia (0-7), subthreshold insomnia (8-14), mild insomnia (15-21) and severe insomnia (22-28). The validity and reliability of Persian version of this questionnaire have been confirmed in the Iranian population (Cronbach's a $>0.8$ and intra-class correlation coefficient $>0.7$ ) [29].

\section{Pittsburgh Sleep Quality Index (PSQI)}

Sleep quality was evaluated using 19-item self-reported PSQI questionnaire that assesses sleep quality over the last 30 days duration [30]. It consisting of 19 items combined for 7 component scores, including subjective sleep quality, sleep latency, sleep duration, habitual sleep efficiency, sleep disturbances, use of sleep medication, and daytime dysfunction. The responses are scored on a 3-point scale, ranging from 0 to 3 . The overall score for sleep quality can be calculated by combination of the 7 component scores, which ranges from 0 to 21. Patients were classified into two groups based on their PSQI score: poor-sleeper group (PSQI>5) and good-sleeper group (PSQI $\leq 5)$. The Persian version of PSQI has also been validated in a previous study by Farrahi Moghaddam et al in 2012 [31].

\section{Quality of Life Questionnaire}

The Short Form Health Survey (SF-36) validated questionnaire was used for evaluating general quality of life. SF-36 categorized into eight subscales: Role Physical, Physical Functioning, General Health, Bodily Pain Social Functioning, Vitality, Role Emotional and Mental Health. Scores of this questionnaire range from 0 to 100. The Persian version of SF-36 was assessed in previous study and indicated good reliability and construct validity [32].

\section{Statistical analysis}

SPSS Statistics for Windows v20 (SPSS, Inc., Chicago, IL) was used for statistical analysis. The normality of variables were analyzed using the Kolmogorov- Smirnov test. Descriptive statistics including mean and standard deviation (SD) were determined for all variables and expressed as mean \pm SD for normally distributed variables and as median and interquartile range (IQR) for nonnormally distributed variables. Also categorical indices were demonstrated by number (\%). Chi-square tests were used to compare the qualitative variables. Two independent sample t-test and Man-Witney test was used to evaluate the significant difference in normal and non-normal variables between two groups, respectively. Finally, multivariate linear regression was performed between hematological parameters and psychological scores. All analyses were considered bilateral, and a p-value of $<0.05$ was considered to be significant.

\section{Results}

The demographic data of the patients are reported in Table 1, which shows the mean age, sex, smoking conditions and underlying diseases of the participants. The number of patients participating in all three subgroups of depression, anxiety, stress, sleep disorders and quality of life questionnaire are listed separately. 
Table 1

General characteristics of study participants.

\begin{tabular}{|c|c|c|c|c|c|c|}
\hline \multirow[t]{3}{*}{ variable } & \multirow{3}{*}{$\begin{array}{l}\text { Depression } \\
\text { Some degree } \\
\text { depression } \\
\mathrm{n}=78\end{array}$} & \multirow{3}{*}{$\begin{array}{l}\text { Anxiety } \\
\text { Some degree } \\
\text { anxiety } \\
n=90\end{array}$} & \multirow{3}{*}{$\begin{array}{l}\text { Stress } \\
\text { Some degree } \\
\text { stress } \\
n=93\end{array}$} & \multicolumn{2}{|l|}{ Sleep } & \multirow{3}{*}{$\begin{array}{l}\text { Quality of } \\
\text { Life } \\
\text { (score<55) } \\
n=58\end{array}$} \\
\hline & & & & $\begin{array}{l}\text { Mild to Sever } \\
\text { Insomnia }\end{array}$ & $\begin{array}{l}\text { Poor Sleep } \\
\text { Quality }\end{array}$ & \\
\hline & & & & $n=28$ & $\mathrm{n}=85$ & \\
\hline \multicolumn{7}{|l|}{ Gender } \\
\hline Male & $44(57.8 \%)$ & $49(55.8 \%)$ & $51(55.7 \%)$ & $13(45.5 \%)$ & $42(49.4 \%)$ & 31 (53.4\%) \\
\hline Female & $34(42.2 \%)$ & $41(44.2 \%)$ & $42(44.3 \%)$ & $15(54.5 \%)$ & 43 (50.6\%) & $27(46.6 \%)$ \\
\hline Age (year) & $60.42 \pm 14.85$ & $59.71 \pm 14.33$ & $60.41 \pm 14.30$ & $57.59 \pm 14.18$ & $61.42 \pm 13.56$ & $60.77 \pm 15.56$ \\
\hline Current smoking & $18(28.5 \%)$ & $20(26.3 \%) *$ & $21(27 \%) *$ & $7(25.0 \%)$ & $16(18.8 \%)$ & $15(25.8 \%)$ \\
\hline \multicolumn{7}{|l|}{ Comorbidity } \\
\hline $\begin{array}{l}\text { Cardiovascular } \\
\text { disease }\end{array}$ & $14(22.2 \%)$ & $17(22.4 \%)$ & $17(21.8 \%)$ & $4(14.2 \%)$ & $14(16.4 \%)$ & $9(15.5 \%)$ \\
\hline Hypertension & $25(39.7 \%)$ & 31 (40.8\%) & $32(41.0 \%)$ & $10(35.7 \%)$ & $30(35.2 \%)$ & $20(34.4 \%)$ \\
\hline Diabetes & $25(39.7 \%)$ & $33(43.4 \%)$ & 35 (44.9\%) & $10(35.7 \%)$ & $32(37.6 \%)$ & $19(32.7 \%)$ \\
\hline \multicolumn{7}{|c|}{ Data presented as Mean \pm SD or $n(\%)$} \\
\hline \multicolumn{7}{|c|}{ Obtained from $t$ test for continuous variables and $\chi 2$ test for categorical variables. } \\
\hline
\end{tabular}

Table 2 shows the relationship between hematological parameters and variables of depression, anxiety, stress, sleep disorders and quality of life. No blood parameters were significantly associated with depression, sleep disorders and quality of life, but in MCHC, WBC and PLR anxiety showed a significant relationship. In the stress subgroup, only RPR was associated with stress. 
Table 2

Hematological parameters in groups of depression, anxiety, Stress, sleep disorders and quality of life.

\begin{tabular}{|c|c|c|c|c|c|c|}
\hline \multirow[t]{4}{*}{ variable } & \multirow{2}{*}{$\begin{array}{l}\text { Depression } \\
\begin{array}{l}\text { Some degree } \\
\text { depression }\end{array}\end{array}$} & \multirow{2}{*}{$\begin{array}{l}\text { Anxiety } \\
\begin{array}{l}\text { Some degree } \\
\text { anxiety }\end{array}\end{array}$} & \multirow{2}{*}{$\begin{array}{l}\text { Stress } \\
\begin{array}{l}\text { Some degree } \\
\text { stress }\end{array}\end{array}$} & \multicolumn{3}{|l|}{ Sleep } \\
\hline & & & & $\begin{array}{l}\text { Mild to Sever } \\
\text { Insomnia }\end{array}$ & $\begin{array}{l}\text { Poor Sleep } \\
\text { Quality }\end{array}$ & $\begin{array}{l}\text { Quality of } \\
\text { Life }\end{array}$ \\
\hline & $\mathrm{n}=78$ & $\mathrm{n}=90$ & $n=93$ & $n=28$ & $\mathrm{n}=85$ & (score $<55$ ) \\
\hline & & & & & & $n=58$ \\
\hline $\operatorname{RBC}\left(10^{12} / \mathrm{L}\right)$ & $4.58 \pm 0.86$ & $4.60 \pm 0.84$ & $4.60 \pm 0.82$ & $4.52 \pm 0.78$ & $4.69 \pm 0.78$ & $4.61 \pm 0.79$ \\
\hline $\begin{array}{l}\text { Hemoglobin } \\
(\mathrm{g} / \mathrm{dl})\end{array}$ & $12.81 \pm 2.58$ & $12.95 \pm 2.43$ & $12.94 \pm 2.41$ & $12.39 \pm 2.37$ & $13.13 \pm 2.30$ & $12.85 \pm 2.38$ \\
\hline Haematocrit & $39.35 \pm 6.59$ & $39.92 \pm 6.59$ & $39.92 \pm 6.51$ & $38.09 \pm 6.61$ & $40.23 \pm 6.16$ & $39.59 \pm 6.52$ \\
\hline MCV (fl) & $86.46 \pm 6.77$ & $87.06 \pm 6.55$ & $87.06 \pm 6.56$ & $87.13 \pm 7.40$ & $86.69 \pm 6.43$ & $87.06 \pm 7.01$ \\
\hline $\mathrm{MCH}(\mathrm{pg})$ & $28.53 \pm 2.68$ & $28.68 \pm 2.52$ & $28.96 \pm 2.49$ & $28.30 \pm 2.98$ & $28.58 \pm 2.51$ & $28.54 \pm 2.67$ \\
\hline $\mathrm{MCHC}(\mathrm{g} / \mathrm{dl})$ & $32.83 \pm 1.89$ & $32.71 \pm 1.68 *$ & $32.71 \pm 1.65$ & $32.54 \pm 1.67$ & $33.42 \pm 6.72$ & $33.54 \pm 7.46$ \\
\hline RDW (\%) & $14.75 \pm 2.32$ & $14.59 \pm 1.99$ & $14.67 \pm 1.99$ & $14.89 \pm 2.05$ & $14.48 \pm 1.79$ & $14.57 \pm 1.82$ \\
\hline PDW (fl) & $14.02 \pm 2.47$ & $13.89 \pm 2.41$ & $13.88 \pm 2.40$ & $13.47 \pm 2.80$ & $13.83 \pm 2.64$ & $13.86 \pm 2.48$ \\
\hline $\begin{array}{l}\text { WBC }\left(10^{3} /\right. \\
\mu \mathrm{L})\end{array}$ & $9.83 \pm 4.72$ & $12.23 \pm 5.43^{*}$ & $11.25 \pm 5.34$ & $8.58 \pm 3.55$ & $9.26 \pm 4.39$ & $9.77 \pm 4.76$ \\
\hline MPV (fl) & $9.70 \pm 3.09$ & $9.71 \pm 2.77$ & $9.72 \pm 2.74$ & $10.33 \pm 0.87$ & $9.78 \pm 2.82$ & $9.59 \pm 3.41$ \\
\hline NLR & $8.15(4.05-13.82)$ & $\begin{array}{l}7.64(4.39- \\
13.65)\end{array}$ & $\begin{array}{l}7.86(4.41- \\
13.87)\end{array}$ & 7.47 (3.78-12.94) & $\begin{array}{l}7.75(4.22- \\
14.43)\end{array}$ & $\begin{array}{l}7.35(3.85- \\
13.61)\end{array}$ \\
\hline RPR & $0.07(0.05-0.11)$ & $\begin{array}{l}0.07(0.06- \\
0.11)\end{array}$ & $\begin{array}{l}0.07(0.05- \\
0.11)^{\star}\end{array}$ & $0.06(0.05-0.09)$ & $\begin{array}{l}0.07(0.05- \\
0.10)\end{array}$ & $\begin{array}{l}0.07(0.05- \\
0.13)\end{array}$ \\
\hline PLR & $\begin{array}{l}17.93(13.34- \\
31.73)\end{array}$ & $\begin{array}{l}28.72(15.88- \\
41.31)^{\star}\end{array}$ & $\begin{array}{l}23.25(14.06- \\
36.67)\end{array}$ & $\begin{array}{l}17.20 \\
27.83)\end{array}$ & $\begin{array}{l}16.1(9.92- \\
30.36)\end{array}$ & $\begin{array}{l}13.57(8.98- \\
26.42)\end{array}$ \\
\hline \multicolumn{7}{|c|}{ Data presented as Mean \pm SD or Median (IQR) } \\
\hline \multicolumn{7}{|c|}{$\begin{array}{l}\text { WBC: white blood cell; RBC: red blood cell; HGB: hemoglobin; HCT: hematocrit; MCV: mean corpuscular volume; MCH: mean } \\
\text { corpuscular hemoglobin; MCHC: mean corpuscular hemoglobin concentration; RDW: red cell distribution width; NLR: Neutrophil } \\
\text { to lymphocyte ratio; RPR: RDW to platelet count ratio; PLR: Platelet lymphocyte ratio. }\end{array}$} \\
\hline \multicolumn{7}{|c|}{${ }^{\star} P<0.05 ; * * P<0.01$} \\
\hline
\end{tabular}

Table 3 shows the linear regression between hematological parameters and psychological score. RDW and PLR were significantly associated with depression and anxiety scores. PLR was also associated with stress. This table shows the age, gender and smoking conditions. Other hematological parameters were not significantly associated with depression, anxiety, stress, sleep disorders and quality of life. 
Table 3

Multivariate linear regression between hematological parameters and psychological scores

\begin{tabular}{|c|c|c|c|c|c|c|c|c|c|c|c|c|}
\hline \multirow{2}{*}{$\begin{array}{l}\text { Haematological } \\
\text { parameters }\end{array}$} & \multicolumn{2}{|c|}{ Depression } & \multicolumn{2}{|l|}{ Anxiety } & \multicolumn{2}{|l|}{ Stress } & \multicolumn{2}{|c|}{ Insomnia } & \multicolumn{2}{|c|}{ Sleep Quality } & \multicolumn{2}{|c|}{ Quality of Life } \\
\hline & $\beta$ & $p$ & $\boldsymbol{\beta}$ & $p$ & $\beta$ & $p$ & $\beta$ & p & $\beta$ & $p$ & $\beta$ & $\mathbf{p}$ \\
\hline $\operatorname{RBC}\left(10^{12} / \mathrm{L}\right)$ & -0.001 & 0957 & -0.011 & 0.562 & 0.003 & 0.846 & -0.224 & 0.245 & 0.150 & 0.498 & 0.009 & 0.951 \\
\hline $\begin{array}{l}\text { Hemoglobin } \\
(\mathrm{g} / \mathrm{dl})\end{array}$ & -0.082 & 0.134 & -0.079 & 0.165 & -0.070 & 0.133 & -0.742 & 0.198 & 0.083 & 0.900 & 0.356 & 0.440 \\
\hline Haematocrit & -0.136 & 0.355 & -0.154 & 0.315 & -0.105 & 0.397 & -2.066 & 0.192 & 0.481 & 0.786 & 0.607 & 0.632 \\
\hline MCV (fl) & -0.197 & 0.147 & -0.114 & 0.421 & -0.207 & 0.070 & 0.646 & 0.658 & -1.246 & 0.463 & 0.241 & 0.836 \\
\hline $\mathrm{MCH}(\mathrm{pg})$ & -0.100 & 0.051 & -0.092 & 0.086 & -0.104 & 0.016 & -0.096 & 0.867 & -0.264 & 0.687 & 0.198 & 0.664 \\
\hline $\mathrm{MCHC}(\mathrm{g} / \mathrm{dl})$ & -0.037 & 0.764 & -0.106 & 0.408 & -0.074 & 0.480 & -0.788 & 0.529 & 1.408 & 0.393 & -0.734 & 0.462 \\
\hline RDW (\%) & 0.086 & 0.045 & 0.100 & 0.038 & 0.064 & 0.103 & 0.374 & 0.454 & 0.500 & 0.331 & -0.144 & 0.717 \\
\hline PDW (fl) & 0.084 & 0.121 & 0.014 & 0.798 & 0.046 & 0.299 & -0.311 & 0.594 & -0.118 & 0.873 & -0.193 & 0.682 \\
\hline WBC $\left(10^{3} / \mu \mathrm{L}\right)$ & 0.021 & 0.841 & -0.158 & 0.143 & -0.093 & 0.296 & -1.414 & 0.204 & -0.865 & 0.475 & -0.398 & 0.657 \\
\hline MPV (fl) & 0.097 & 0.207 & 0.007 & 0.926 & 0.006 & 0.923 & 0.739 & 0.269 & 0.079 & 0.926 & 0.344 & 0.542 \\
\hline NLR & -0.375 & 0.058 & -0.242 & 0.207 & -0.219 & 0.168 & -1.156 & 0.553 & 1.282 & 0.601 & 1.133 & 0.472 \\
\hline RPR & 0.003 & 0.241 & 0.004 & 0.107 & 0.003 & 0.185 & -0.017 & 0.535 & -0.005 & 0.892 & 0.010 & 0.649 \\
\hline PLR & 1.326 & 0.016 & 1.356 & 0.010 & 1.102 & 0.012 & 4.146 & 0.445 & 1.078 & 0.876 & -3.372 & 0.440 \\
\hline \multicolumn{13}{|c|}{$\begin{array}{l}\text { WBC: white blood cell; RBC: red blood cell; HGB: hemoglobin; HCT: hematocrit; MCV: mean corpuscular volume; MCH: mean } \\
\text { corpuscular hemoglobin; MCHC: mean corpuscular hemoglobin concentration; RDW: red cell distribution width; NLR: Neutrophil } \\
\text { to lymphocyte ratio; RPR: RDW to platelet count ratio; PLR: Platelet lymphocyte ratio. }\end{array}$} \\
\hline
\end{tabular}

\section{Discussion}

Our results suggest that higher depression and anxiety scores in COVID-19 patients are associated with an enhanced inflammatory state, as assessed by higher hematological inflammatory markers including RDW and PLR. However, PLR was also associated with stress in participants.

There are several theoretically viable hypotheses that can be used to justify the potential prognostic role of anisocytosis in COVID19 , including direct cytopathic injury disease associated of circulating erythrocytes or their bone marrow precursors, indirect erythrocyte damage caused by hemolytic anemia or intravascular coagulopathy, and profound iron metabolism disruption caused by the sustained inflammatory response [15]. All of these factors would eventually lead to deranged erythrocyte biology and explain the wide range of erythrocyte sizes in circulation. The dramatic derangement of erythrocyte biology in patients with SARS-CoV-2 infection could also be explained by a coexisting indirect injury. First, cases of autoimmune hemolytic anemia have been linked to SARS-CoV-2 infection [33] a phenomenon that has been attributed to the high molecular similarity between the SARS-CoV-2 spike protein and the protein ankyrin 1 found on RBC surfaces [34]In COVID-19 patients who develop severe or critical illness, intravascular coagulopathy, either localized to the lung parenchyma or disseminated, is also common [35]. The formation of micro- and macrothrombi in various blood veins is a well-known cause of erythrocyte injury, which would contribute to the existence of RBCs with numerous morphological defects high size heterogeneity in the circulation [36].

Coronavirus infection is associated with alterations in the white blood cell count. Alteration in the white blood cell count are linked to Coronavirus infection. A Wuhan study found no significant change in WBC counts, a reduction in the severity of symptoms, and a complete recovery, especially in individuals with no co-morbidities. So, when comparing severe and non-severe patients, total leukocyte counts have a wide range of findings in the literature. The mechanism behind this phenomenon is unknown, while some 
researchers believe it is linked to the worsening of cytokine storm syndrome, a clinical state of hyper inflammation caused by the production of pro-inflammatory cytokines and inflammatory cytokines. Multi organ failure, which can be dangerous, can occur as a result of cytokine storm syndrome [16].

A higher WBC count has been identified in depressed and anxious people in several investigations [10, 37]. After 5 years of follow-up, the participants with recurring depressive symptoms have higher WBC counts [10]. In one study results showed that after adjusting for age and cigarette smoking, there is still a link between major depressive illness and leukocyte counts for males but not for women [38]. Furthermore, Pitsavos et al. discovered that anxiety score is positively connected with WBC count in women, but not in men [39]. Another study found that WBC count and related indicators are associated with depressed symptoms, particularly in women [40]. In depressed patients, Darko and colleagues discovered relative lymphopenia, absolute neutrophilia, and leukocytosis. However, the authors speculated that leukocytosis and neutrophilia could be a side effect of taking specific medications [41]. Similarly, when compared to control subjects, newly diagnosed antidepressant-naive patients had a decreased lymphocyte count [42]. A number of studies have demonstrated a link between depression and inflammation, and some have even suggested that depression is an inflammatory disease. Since WBC count is an independent predictor of atherosclerosis and cardiovascular disease, it's possible that higher WBC counts or the related inflammatory state could explain some of the elevated cardiac events shown in depressed people $[43,44]$.

NLR was considerably higher in ICU patients than in non-ICU patients, indicating that it is a useful severity indicator. NLR was also proven to be an effective predictor of critical disease risk in other trials[45]. Another study indicated that patients with NLR $>3$ were more likely to have severe illness in the population under 50 years old. All of these investigations concluded that the NLR was the most important prognostic factor for patients with serious illnesses [46].

Another study found that patients with major depressive disorder had significantly higher RDW and Neutrophil/Lymphocyte ratio (NLR) levels than the control group [47, 48]. May and colleagues also discovered a link between rising RDW levels and a prospective depression diagnosis, which remained after controlling for risk factors, medications, and indicators of other disease states [49]. $\mathrm{MCV}, \mathrm{MCH}, \mathrm{MCHC}$, and RDW were not significantly different between major depressed subjects and normal controls in another study [50]. RDW has received a lot of attention in the last decade because of its ability to successfully predict the risk of death in the general population [51], patients with non-cardiovascular critical illness, sepsis, pneumonia, and other respiratory tract infections [52, 53]. It is not surprising that our findings show RDW to be a significant and independent predictor of disease severity and kidney injury in patients infected with SARS-CoV-2. Remarkably, after managing for confounding variables, an increased value of this laboratory variable was associated with a 9.2- and 16.0-fold higher risk of estimating severe illness and AKI, respectively, with predictive precision as high as 73 percent and 80 percent and suggested that RDW should be part of routine laboratory assessment and monitoring of COVID-19 [15]. Wang et al. measured RDW in 45 COVID-19 patients with moderate to severe illness over a nearly 20-day period in this latter study. Patients with severe COVID-19 had significantly higher RDW values than those with a milder form of the disease. Furthermore, both RDWs were found to be significant predictors of severe illness, with diagnostic accuracy ranging from 65 to 76 percent [54].

Many other research, however, reveal that thrombocytopenia is a common characteristic in severe COVID-19 patients. Although, few investigations found no variations in platelet count between patients with severe disease and those with mild disease. Regarding the authors' conflicting observations, new research suggests that coagulopathy is a known hazard of COVID-19 [55]. The PLR, a general inflammatory marker, represents a concurrent interaction of platelet count and lymphocyte count, and it indicates aggregation as well as inflammatory pathways. It has been reported to be increased in response to a variety of acute and chronic proinflammatory conditions, and it has been linked to a poor prognosis in individuals with COPD and carcinomas [19, 55-57]. A previous study has found a relationship between elevated PLR and a poor prognosis of sepsis-induced acute renal injury and mortality [58]. In COVID19 patients, the change in PLR from baseline appears to be linearly associated with severity of illness and length of hospital stay [59]. PLR appeared as an independent predictive factor for prolonged hospitalization in one study's multivariate analysis. A high PLR may indicated a more intense cytokine storm as a result of increased platelet activation [60]. No major differences in PLR were seen in Tiwari's investigative process, as was observed in the current study. However, because platelets are a dynamic variable, the validity of PLR can only be determined by collecting follow-up samples at different time points [16].

\section{Conclusion}


In conclusion, this study showed a positive association between depression/anxiety/stress symptoms and levels of hematological inflammatory markers including PLR and RDW, which persisted despite adjustment by potential confounders.

\section{Abbreviations}

Complete blood count: CBC

Depression anxiety stress scales: DASS

Hematocrit: HCT

Hemoglobin: HGB

Insomnia Severity Index: ISI

Mean corpuscular hemoglobin concentration: MCHC

Mean corpuscular hemoglobin: $\mathrm{MCH}$

Mean corpuscular volume: MCV

Mean platelet volume: MPV

Neutrophil to Lymphocyte Ratio: NLR

Pittsburgh Sleep Quality Index: PSQI

Platelet distribution width: PDW

Platelet to Lymphocyte Ratio: PLR

Platelet: PLT

Red blood cell: RBC

Red cell distribution width: RDW

White blood cell: WBC

\section{Declarations}

\section{Ethics declarations}

The authors confirm that all procedures contributing to this work was based on the ethical standards laid down in the 1964 Declaration of Helsinki, as revised in 2008.

\section{Ethics approval and consent to participate}

The Ethics Committee of MUMS (Mashhad University of Medical Sciences), Mashhad, Iran, approved the trial (Ethic no: IR.MUMS.REC.1399.237). Informed written consent was obtained from all participants included in the study.

\section{Consent for publication}

Not applicable.

\section{Availability of data and materials}

The datasets used and/or analyzed during the current study are available from the corresponding author on reasonable request. 
Competing interests

The authors declare that they have no conflict of interests

Funding

This work was supported by Mashhad University of Medical Sciences, Iran (Grant number: 981873).

Authors' contributions

MGH initially conceptualized and designed the study, ZKH, MR, EH and MA upgraded the design. The manuscript was written by RR. PA and PSH were responsible for the design optimizing and statistical analysis. NA, NV and SR contribute sampling. GF performed English editing. All authors read and approved the final manuscript.

\section{Acknowledgements}

We sincerely thank all patients participating in this study in advance, because this study would not be possible without their cooperation. We also express our appreciation to those who helped us in in this study.

\section{References}

1. Holmes EA, O'Connor RC, Perry VH, Tracey I, Wessely S, Arseneault L, Ballard C, Christensen H, Silver RC, Everall I: Multidisciplinary research priorities for the COVID-19 pandemic: a call for action for mental health science. The Lancet Psychiatry 2020, 7(6):547-560.

2. Hopkins J: COVID-19 dashboard by the center for systems science and engineering (CSSE) at Johns Hopkins University (JHU). Baltimore: Johns Hopkins University 2020.

3. Yao H, Chen J-H, Xu Y-F: Patients with mental health disorders in the COVID-19 epidemic. 2020.

4. Reger MA, Stanley IH, Joiner TE: Suicide mortality and coronavirus disease 2019-a perfect storm? JAMA psychiatry 2020, 77(11):1093-1094.

5. Meduri GU, Kohler G, Headley S, Tolley E, Stentz F, Postlethwaite A: Inflammatory cytokines in the BAL of patients with ARDS: persistent elevation over time predicts poor outcome. Chest 1995, 108(5):1303-1314

6. Michopoulos V, Powers A, Gillespie CF, Ressler KJ, Jovanovic T: Inflammation in fear-and anxiety-based disorders: PTSD, GAD, and beyond. Neuropsychopharmacology 2017, 42(1):254-270.

7. Uzun N, Akıncı MA: Hemogram parameters in childhood anxiety disorders: Could anxiety disorders be related with inflammation? Medical Hypotheses 2021, 146:110440.

8. Baune BT, Smith E, Reppermund S, Air T, Samaras K, Lux O, Brodaty H, Sachdev P, Trollor JN: Inflammatory biomarkers predict depressive, but not anxiety symptoms during aging: the prospective Sydney Memory and Aging Study. Psychoneuroendocrinology 2012, 37(9):1521-1530.

9. Danner M, KasI SV, Abramson JL, Vaccarino V: Association between depression and elevated C-reactive protein. Psychosomatic medicine 2003, 65(3):347-356.

10. Duivis HE, Kupper N, Penninx BW, Na B, de Jonge P, Whooley MA: Depressive symptoms and white blood cell count in coronary heart disease patients: Prospective findings from the Heart and Soul Study. Psychoneuroendocrinology 2013, 38(4):479-487.

11. Nakanishi N, Yoshida H, Matsuo Y, Suzuki K, Tatara K: White blood-cell count and the risk of impaired fasting glucose or Type II diabetes in middle-aged Japanese men. Diabetologia 2002, 45(1):42-48.

12. Jee SH, Park JY, Kim H-S, Lee TY, Samet JM: White blood cell count and risk for all-cause, cardiovascular, and cancer mortality in a cohort of Koreans. American journal of epidemiology 2005, 162(11):1062-1069.

13. McPherson RA, Msc M, Pincus MR: Henry's clinical diagnosis and management by laboratory methods E-book: Elsevier Health Sciences; 2021.

14. Kalay N, Aytekin M, Kaya MG, Ozbek K, Karayakalı M, Söğüt E: The relationship between inflammation and slow coronary flow: increased red cell distribution width and serum uric acid levels. Turk Kardiyol Dern Ars 2011, 39(6):463-468. 
15. Henry BM, Benoit JL, Benoit S, Pulvino C, Berger BA, Olivera MHSd, Crutchfield CA, Lippi G: Red blood cell distribution width (RDW) Predicts COVID-19 severity: a prospective, observational study from the cincinnati SARS-CoV-2 emergency department cohort. Diagnostics 2020, 10(9):618.

16. Sahu P, Rai A, Sahu S, Raut K: Haematological Findings and Pattern Analysis in Patients with COVID-19 Infection. Int J Cur Res Rev/ Vol 2021, 13(06):36.

17. Gallagher MW, Zvolensky MJ, Long LJ, Rogers AH, Garey L: The impact of Covid-19 experiences and associated stress on anxiety, depression, and functional impairment in American adults. Cognitive Therapy and Research 2020, 44(6):1043-1051.

18. Zahorec R: Ratio of neutrophil to lymphocyte counts-rapid and simple parameter of systemic inflammation and stress in critically ill. Bratislavske lekarske listy 2001, 102(1):5-14.

19. Erre GL, Paliogiannis P, Castagna F, Mangoni AA, Carru C, Passiu G, Zinellu A: Meta-analysis of neutrophil-to-lymphocyte and platelet-to-lymphocyte ratio in rheumatoid arthritis. European journal of clinical investigation 2019, 49(1):e13037.

20. Ye Z, Ai X, Liao Z, You C, Cheng Y: The prognostic values of neutrophil to lymphocyte ratio for outcomes in chronic obstructive pulmonary disease. Medicine 2019, 98(28).

21. Bustan Y, Drapisz A, Dor DHB, Avrahami M, Schwartz-Lifshitz M, Weizman A, Barzilay R: Elevated neutrophil to lymphocyte ratio in non-affective psychotic adolescent inpatients: Evidence for early association between inflammation and psychosis. Psychiatry research 2018, 262:149-153.

22. Ekinci O, Ekinci A: The connections among suicidal behavior, lipid profile and low-grade inflammation in patients with major depressive disorder: a specific relationship with the neutrophil-to-lymphocyte ratio. Nordic journal of psychiatry 2017, 71(8):574580.

23. Horstman LL, Jy W, Ahn YS, Zivadinov R, Maghzi AH, Etemadifar M, Alexander JS, Minagar A: Role of platelets in neuroinflammation: a wide-angle perspective. Journal of neuroinflammation 2010, 7(1):1-22.

24. Kumarasamy C, Sabarimurugan S, Madurantakam RM, Lakhotiya K, Samiappan S, Baxi S, Nachimuthu R, Gothandam KM, Jayaraj R: Prognostic significance of blood inflammatory biomarkers NLR, PLR, and LMR in cancer-A protocol for systematic review and meta-analysis. Medicine 2019, 98(24).

25. Özdin S, Sarisoy G, Böke Ö: A comparison of the neutrophil-lymphocyte, platelet-lymphocyte and monocytelymphocyte ratios in schizophrenia and bipolar disorder patients-a retrospective file review. Nordic journal of psychiatry 2017, 71(7):509-512.

26. Henry JD, Crawford JR: The short-form version of the Depression Anxiety Stress Scales (DASS-21): Construct validity and normative data in a large non-clinical sample. British journal of clinical psychology 2005, 44(2):227-239.

27. Sahebi A, Asghari MJ, Salari RS: Validation of depression anxiety and stress scale (DASS-21) for an Iranian population. 2005.

28. Morin CM, Belleville G, Bélanger L, Ivers H: The Insomnia Severity Index: psychometric indicators to detect insomnia cases and evaluate treatment response. Sleep 2011, 34(5):601-608.

29. Yazdi Z, Sadeghniiat-Haghighi K, Zohal MA, Elmizadeh K: Validity and reliability of the Iranian version of the insomnia severity index. The Malaysian journal of medical sciences: MJMS 2012, 19(4):31.

30. Buysse D, Reynolds C, Monk T, Berman S: R. CF III,... Kupfer DJ (1989). The Pittsburgh Sleep Quality Index: a new instrument for psychiatric practice and research Psychiatry Research, 28(2):193-213.

31. Moghaddam JF, Nakhaee N, Sheibani V, Garrusi B, Amirkafı A: Reliability and validity of the Persian version of the Pittsburgh Sleep Quality Index (PSQI-P). Sleep and Breathing 2012, 16(1):79-82.

32. Montazeri A, Goshtasebi A, Vahdaninia M, Gandek B: The Short Form Health Survey (SF-36): translation and validation study of the Iranian version. Quality of life research 2005, 14(3):875-882.

33. Lazarian G, Quinquenel A, Bellal M, Siavellis J, Jacquy C, Re D, Merabet F, Mekinian A, Braun T, Damaj G: Autoimmune haemolytic anaemia associated with COVID-19 infection. British journal of haematology 2020.

34. Angileri F, Légaré S, Gammazza AM, de Macario EC, Macario AJ, Cappello F: Is molecular mimicry the culprit in the autoimmune haemolytic anaemia affecting patients with COVID-19? British journal of haematology 2020.

35. Lippi G, Sanchis-Gomar F, Henry BM: COVID-19: unravelling the clinical progression of nature's virtually perfect biological weapon. Annals of translational medicine 2020, 8(11).

36. Martinelli N, Montagnana M, Pizzolo F, Friso S, Salvagno GL, Forni GL, Gianesin B, Morandi M, Lunardi C, Lippi G: A relative ADAMTS13 deficiency supports the presence of a secondary microangiopathy in COVID 19. Thrombosis Research 2020, 
193:170-172.

37. Sunbul EA, Sunbul M, Yanartas O, Cengiz F, Bozbay M, Sari I, Gulec H: Increased neutrophil/lymphocyte ratio in patients with depression is correlated with the severity of depression and cardiovascular risk factors. Psychiatry investigation 2016, 13(1):121.

38. Surtees P, Wainwright N, Day N, Luben R, Brayne C, Khaw K-T: Association of depression with peripheral leukocyte counts in EPIC-Norfolk-role of sex and cigarette smoking. Journal of psychosomatic research 2003, 54(4):303-306.

39. Pitsavos C, Panagiotakos DB, Papageorgiou C, Tsetsekou E, Soldatos C, Stefanadis C: Anxiety in relation to inflammation and coagulation markers, among healthy adults: the ATTICA study. Atherosclerosis 2006, 185(2):320-326.

40. Beydoun M, Beydoun H, Dore G, Canas J, Fanelli-Kuczmarski M, Evans M, Zonderman A: White blood cell inflammatory markers are associated with depressive symptoms in a longitudinal study of urban adults. Translational psychiatry 2016, 6(9):e895e895.

41. Darko DF, Rose J, Gillin JC, Golshan S, Baird SM: Neutrophilia and lymphopenia in major mood disorders. Psychiatry research 1988, 25(3):243-251.

42. Garcia-Rizo C, Fernandez-Egea E, Miller BJ, Oliveira C, Justicia A, Griffith JK, Heaphy CM, Bernardo M, Kirkpatrick B: Abnormal glucose tolerance, white blood cell count, and telomere length in newly diagnosed, antidepressant-naive patients with depression. Brain, behavior, and immunity 2013, 28:49-53.

43. Berk M, Williams LJ, Jacka FN, O'Neil A, Pasco JA, Moylan S, Allen NB, Stuart AL, Hayley AC, Byrne ML: So depression is an inflammatory disease, but where does the inflammation come from? BMC medicine 2013, 11(1):1-16.

44. Vetter ML, Wadden TA, Vinnard C, Moore RH, Khan Z, Volger S, Sarwer DB, Faulconbridge LF: Gender differences in the relationship between symptoms of depression and high-sensitivity CRP. International journal of obesity 2013, 37(1):S38-S43.

45. Li Q, Ding X, Xia G, Geng Z, Chen F, Wang L, Wang Z: A simple laboratory parameter facilitates early identification of COVID-19 patients. MedRxiv 2020.

46. Liu J, Liu Y, Xiang P, Pu L, Xiong H, Li C, Zhang M, Tan J, Xu Y, Song R: Neutrophil-to-lymphocyte ratio predicts critical illness patients with 2019 coronavirus disease in the early stage. Journal of Translational Medicine 2020, 18:1-12.

47. Demircan F, Gözel N, Kılınç F, Ulu R, Atmaca M: The impact of red blood cell distribution width and neutrophil/lymphocyte ratio on the diagnosis of major depressive disorder. Neurology and therapy 2016, 5(1):27-33.

48. Shafiee M, Tayefi M, Hassanian SM, Ghaneifar Z, Parizadeh MR, Avan A, Rahmani F, Khorasanchi Z, Azarpajouh MR, Safarian $\mathrm{H}$ : Depression and anxiety symptoms are associated with white blood cell count and red cell distribution width: a sex-stratified analysis in a population-based study. Psychoneuroendocrinology 2017, 84:101-108.

49. May HT, Anderson JL, Muhlestein JB, Bair TL, Knight S, Horne BD: Red cell distribution width and depression among patients undergoing angiography. In.: Am Heart Assoc; 2013.

50. Maes M, Lambrechts J, Bosmans E, Jacobs J, Suy E, Vandervorst C, De Jonckheere C, Minner B, Raus J: Evidence for a systemic immune activation during depression: results of leukocyte enumeration by flow cytometry in conjunction with monoclonal antibody staining. Psychological medicine 1992, 22(1):45-53.

51. Patel KV, Semba RD, Ferrucci L, Newman AB, Fried LP, Wallace RB, Bandinelli S, Phillips CS, Yu B, Connelly S: Red cell distribution width and mortality in older adults: a meta-analysis. Journals of Gerontology Series A: Biomedical Sciences and Medical Sciences 2010, 65(3):258-265.

52. Hu Z-D, Lippi G, Montagnana M: Diagnostic and prognostic value of red blood cell distribution width in sepsis: a narrative review. Clinical biochemistry 2020, 77:1-6.

53. Luo R, Hu J, Jiang L, Zhang M: Prognostic value of red blood cell distribution width in non-cardiovascular critically or acutely patients: a systematic review. PLoS One 2016, 11(12):e0167000.

54. Wang C, Deng R, Gou L, Fu Z, Zhang X, Shao F, Wang G, Fu W, Xiao J, Ding X: Preliminary study to identify severe from moderate cases of COVID-19 using combined hematology parameters. Annals of translational medicine 2020, 8(9).

55. Veronese N, Demurtas J, Yang L, Tonelli R, Barbagallo M, Lopalco P, Lagolio E, Celotto S, Pizzol D, Zou L: Use of corticosteroids in coronavirus disease 2019 pneumonia: a systematic review of the literature. Frontiers in medicine 2020, 7:170.

56. Li B, Zhou P, Liu Y, Wei H, Yang X, Chen T, Xiao J: Platelet-to-lymphocyte ratio in advanced cancer: review and meta-analysis. Clinica Chimica Acta 2018, 483:48-56. 
57. Liu L, Shao Z, Yu H, Zhang W, Wang H, Mei Z: Is the platelet to lymphocyte ratio a promising biomarker to distinguish acute appendicitis? Evidence from a systematic review with meta-analysis. PloS one 2020, 15(5):e0233470.

58. Chen Y, Feng F, Li M, Yuan J-J, Chang X-N, Wei B-H, Du H, Dong C-M: Relationship between platelet/lymphocyte ratio and prognosis of patients with septic acute kidney injury: A pilot study. Journal of the Chinese Medical Association 2020, 83(11):1004.

59. Qu R, Ling Y, Zhang Yhz, Wei Ly, Chen X, Li Xm, Liu Xy, Liu Hm, Guo Z, Ren H: Platelet-to-lymphocyte ratio is associated with prognosis in patients with coronavirus disease-19. Journal of medical virology 2020, 92(9):1533-1541.

60. Fan BE: Hematologic parameters in patients with COVID-19 infection: a reply. American journal of hematology 2020. 